\title{
EFFECT OF HEAT TREATMENT ON THE CORROSION BEHAVIOR OF AI-10\% WT Mg ALLOYS
}

\author{
Zermane Samira $^{1)}$, Chala Abdelouahed ${ }^{1)}$, Belahssen Okba ${ }^{1) *}$ \\ 1) Physic Laboratory of Thin Films and Applications (LPCMA), University of Biskra, 07000, \\ Algeria
}

Received: 05.05.2017

Accepted: 03.08.2017

*Corresponding author: e-mail: belahssenokba@ gmail.com , Tel.: +213 7746376 26, Physic

Laboratory of Thin Films and Applications (LPCMA), University of Biskra, 07000, Algeria

\begin{abstract}
In the present investigation, the effect of heat treatment on the electrochemical behavior of Al$10 \%$ wt $\mathrm{Mg}$ alloy in $3.5 \% \mathrm{wt} \mathrm{NaCl}$ is studied by different electrochemical techniques such as polarization technique (Tafel plot) and electrochemical impedance spectroscopy. It has been shown that the corrosion resistant of the alloy decreased with the ageing treatment at $250{ }^{\circ} \mathrm{C}$ for $24 \mathrm{~h}$. However, this latter increased with naturally ageing. The SEM (electron microscope) and Energy Dispersive EDS characterization have shown that the alloy with the two treatments of ageing became susceptible to the pitting corrosion.
\end{abstract}

Keywords: Al-Mg alloy; ageing treatment; corrosion; microstructure

\section{Introduction}

The addition of selected elements to pure aluminum enhances its; mechanical, physical, and chemical properties. The addition of magnesium to aluminium gives good hardness, good weldability and favorable corrosion resistance. Alloys in which magnesium is the primary alloying element are used in ship hulls, passage boards and other products exposed to marine environments because of their excellent corrosion resistance [1,2]. Non-heat treatable Al-Mg alloys (5xxx series) have better formability but; on the other hand, they are not precipitation hardenable, and that may limit their use in certain areas, and heat treatment provides alloys with interesting physical and mechanical properties [3]. Increasing the percentage of $\mathrm{Mg}$ in the aluminium matrix gives an alloy with good hardness, but very susceptible to intergranular corrosion and stress corrosion [2]. However, a percentage greater than $3 \% \mathrm{wt} \mathrm{Mg}$ in the aluminium $\alpha$ matrix favours the precipitation of the $\beta\left(\mathrm{Al}_{3} \mathrm{Mg}_{2}\right)$ phase on the grain boundary and the latter is anodic with respect to the aluminium matrix and corrodes preferentially [4]. The corrosion behavior of Al-Mg alloys is controlled by the morphology and distribution of its precipitates on the grain boundary [2,3]. It was discovered that the kind, size, and distribution of the intermetallic phases located along the grain boundaries are regarded as the main factors responsible for the susceptibility to stress corrosion cracking [5]. A thin layer of invisible oxide forms immediately when the aluminium surfaces are exposed to the atmosphere, which protects the metal from further oxidation. Therefore the alloy becomes passive. But this behaviour can be interrupted by the existence of pitting corrosion, which produces a severe problem $[2,6]$. In the present work, the electrochemical behaviour of the Al-10\%wtMg alloy was investigated at two different ageing treatments by means of polarisation curves, electrochemical impedance spectroscopy, characterised by SEM and EDS. 


\section{Experimental material and methods}

The Chemical composition of the alloy used in this study is given in Table $\mathbf{1}$.

These samples were heat treated as follows: homogenization at $430{ }^{\circ} \mathrm{C}$ during 17 hours, followed by rapid quenching in ice water (rapid cooling). A few samples are matured at an ambient temperature (naturally ageing), and others are aged at $250{ }^{\circ} \mathrm{C}$ for 24 hours. For the metallographic characterization, and corrosion tests, samples were polished and etched with 2 $\mathrm{mL}(\mathrm{HF}), 3 \mathrm{~mL}(\mathrm{HCl}), 5 \mathrm{~mL}\left(\mathrm{NHO}_{3}\right)$ and $180 \mathrm{~mL}\left(\mathrm{H}_{2} \mathrm{O}\right)$. A scanning electron microscopy (FEI Quanta 200 SEM) equipped with EDS was used to examine both morphology and elemental analysis of the samples. Corrosion behaviour was studied by using electrochemical impedance spectroscopy,and Tafel extrapolation in $3.5 \%$ wt $\mathrm{NaCl}$ solution. The electrochemical tests are carried out using a PGZ301 potentiostat connected to a data acquisition system equipped with software (EC-LAB V10.02). the working electrode was the test sample, the counter electrode was platinum, and the reference electrode was $\mathrm{Hg} / \mathrm{HgO} / 1 \mathrm{M} \mathrm{KOH}$. All the electrochemical measurements were performed under same conditions $(\mathrm{pH}=6.5$ the $\mathrm{pH}$ evolves freely during the experiment, after 25 minutes of immersion, freely exposed to the atmosphere and ambient temperature). The polarisation experiments were carried out using a scan rate of $1 \mathrm{mV} / \mathrm{s}$. Electrochemical impedance spectroscopy (EIS) measurements were obtained at the open circuit potential (OCP) in a frequency range of $10 \mathrm{kHz}-100 \mathrm{mHz}$, with an applied AC signal amplitude perturbation of $10 \mathrm{mV}$.

Table 1 Chemical composition of $\mathrm{Al}-10 \%$ wt $\mathrm{Mg}$ (compositions in wt \%)

\begin{tabular}{|c|c|c|c|c|c|c|c|c|c|}
\hline Elements & $\mathrm{Al}$ & $\mathrm{Mg}$ & $\mathrm{Fe}$ & $\mathrm{Mn}$ & $\mathrm{Cu}$ & $\mathrm{Si}$ & $\mathrm{Zn}$ & $\mathrm{Sn}$ & $\mathrm{Ti}$ \\
\hline $\mathrm{wt} \%$ & 88.55 & 9.94 & 0.4 & 0.08 & 0.03 & 0.6 & 0.4 & 0.03 & 0.04 \\
\hline
\end{tabular}

\section{Results and discussion}

\subsection{Microstructure}

Fig. 1a shows the microstructure of the alloy with ageing at room temperature. The morphology of sample exhibit a structure with pores (defects) formed during the solidification and with the various intermetallic particles, one being dark and the other is clear. The EDS analysis of two intermetallic particles separately reveals that: the first intermetallic particle (dark) is rich in $\mathrm{Si}$ (Table 2) and the other rich in Fe (Table 3) (see Fig. 1a), as related in [6]. After the corrosion test, the Fig. 1b shows that there is localised corrosion with the existence of the oxide layer. Examination of this sample by EDS is given in Table 4 shows that there is a large dissolute of $\mathrm{Mg}$ and $\mathrm{Al}$ where it appears $\mathrm{O}$ and $\mathrm{Cl}$ with a large quantity, which confirms the existence of the pits. The Fe and the Si form of the cathode intermetallic particles (potential noble with respect to the aluminum matrix) can form microcells, and a localised attack of Al. The presence of the porosities on the surface of the material may be the seat of a localised attack thus reducing the resistance to corrosion of this material [7].

Table 2 The EDS analysis result of the particle 1

\begin{tabular}{|c|c|c|c|c|c|c|}
\hline Elements & $\mathrm{C}$ & $\mathrm{O}$ & $\mathrm{F}$ & $\mathrm{Mg}$ & $\mathrm{Al}$ & $\mathrm{Si}$ \\
\hline $\mathrm{Wt} \%$ & 5.30 & 14.84 & 1.75 & 5.05 & 36.58 & 36.47 \\
\hline
\end{tabular}

Table 3 The EDS analysis result of the particle 2

\begin{tabular}{|c|c|c|c|c|c|c|c|}
\hline Elements & $\mathrm{C}$ & $\mathrm{O}$ & $\mathrm{Mg}$ & $\mathrm{Al}$ & $\mathrm{Mn}$ & $\mathrm{Fe}$ & $\mathrm{Cu}$ \\
\hline $\mathrm{Wt} \%$ & 4.36 & $2 . .37$ & 2.31 & 59.08 & 4.21 & 26.87 & 0.80 \\
\hline
\end{tabular}


Table 4 Chemical composition of $\mathrm{Al}-10 \%$ wtMg with ageing naturally after the corrosion test

\begin{tabular}{|c|c|c|c|c|c|c|c|}
\hline Elements & $\mathrm{C}$ & $\mathrm{O}$ & $\mathrm{Mg}$ & $\mathrm{Al}$ & $\mathrm{Si}$ & $\mathrm{Cl}$ & $\mathrm{Ca}$ \\
\hline $\mathrm{Wt} \%$ & 6.35 & 21.68 & 2.71 & 34.27 & 0.37 & 33.10 & 1.51 \\
\hline
\end{tabular}
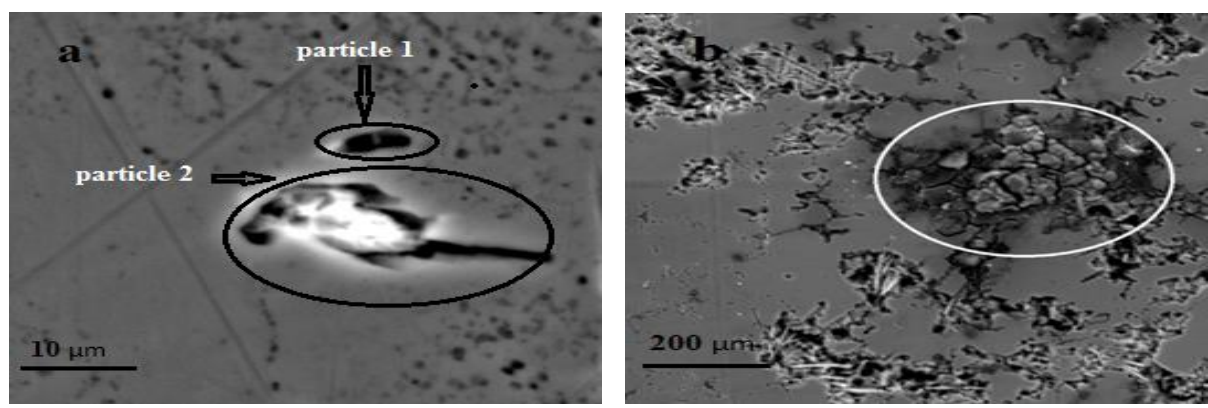

Fig. 1 SEM micrographs of Al-10\%Mg alloy with the ageing at the room temperature (a) with intermetallic particles that exist in the matrix. (b) After the corrosion test

Mizuno et al. [8], the activity of $\mathrm{Si}$ is zero, it can form on the Si-rich phases of the oxides of $\mathrm{SiO}$, and the latter can prevent the cathodic reaction. Phases rich in $\mathrm{Fe}\left(\mathrm{Al}_{3} \mathrm{Fe}\right)$ are nobler than the matrix of aluminium, play the role of cathodes, the potential difference induces galvanic currents which translate by a localised attack on the peripheral of these phases [9]. From these results we can conclude that; the porosity has favoured the formation of the pits, so there is a high absorption of the $\mathrm{Cl}$ following the results of the EDS, also we can confirm that the corrosion is due to the intermetallic particles. The ageing at $250{ }^{\circ} \mathrm{C}$ is intended to have the precipitation of the equilibrium phase $\mathrm{Al}_{3} \mathrm{Mg}_{2}$. (Fig. 2a) shows that the precipitation of the $\beta$ phase may be continuous, and also discontinuous on the grain boundaries as related by Y. Zhao et al. [10]. After the polarisation test, we notice that the corrosion is localised, and in some areas of the matrix the corrosion is intergranular, where there is the formation of pitting, Fig. $2 \mathbf{b}$ shows a layer of the oxide which covers the other uncorroded areas. The $\beta\left(\mathrm{Al}_{3} \mathrm{Mg}_{2}\right)$ phase produces zones of localised corrosion which leads to the formation of pits in the grains and to the grain boundaries where $\beta$ precipitates exist. However, Fig. $2 \mathbf{b}$ shows that the corrosion is intergranular and occurs much more on the precipitates free zones. T. Minoda et al. [11] reported that there is dissolution of the zones PFZs because of the difference between the potential of these zones PFZs and the grain wedges of the precipitates in the matrix.

\subsection{Electrochemical study}

\subsubsection{Polarisation measurements}

Fig. 3 presents the polarisation behaviour of $\mathrm{Al}-10 \% \mathrm{wtMg}$ alloy for the two treatments ageing at room temperature and at $250^{\circ} \mathrm{C}$ during $24 \mathrm{~h}$. The cathodic polarisation curves were attributed to the water reduction, in aerated $\mathrm{NaCl}$ solution this reaction cause in enrichment in $\mathrm{OH}^{-}$ions which cause a local increase in $\mathrm{pH}$ [12]. And the anodic polarisation curves were ascribed to the dissolution of Al, of which the corrosion current density rapidly increases with increasing anodic potential. However, the anodic side exhibits a passive region, where the corrosion current density increases slowly with increasing anodic potential, so on this anodic curve there are two breakdowns potential, Corrosion potential (more active), and pitting corrosion (more noble) Tab. 5. [13]. The corrosion potential Ec, corrosion current density $\mathbf{i}_{\mathbf{c}}$, and corrosion resistance 
Rc, were calculated from Tafel extrapolation and presented in Tab. 5.The results show the ageing at $250^{\circ} \mathrm{C}$ during $24 \mathrm{~h}$ did not improve the corrosion resistance of the alloy, and the anodic
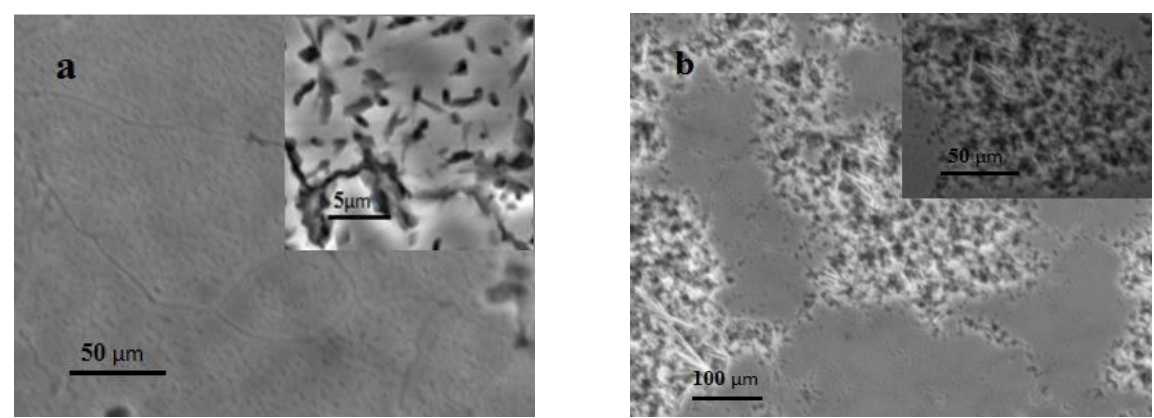

Fig. 2 Microstructures observations of the Al-10\% Mg alloy with the ageing at $250{ }^{\circ} \mathrm{C}$ for 24 , (a): before and, (b): after corrosion testing

current density is higher, but the ageing at room temperature leads to an increase in the corrosion resistance of the alloy with lowest current density. On the other hand, for the alloy with ageing at $250^{\circ} \mathrm{C}$, the corrosion potential became noble, and the Epit (pits potential) shifts towards more negative values as related by W.J. Liang et al. [14]. This observation can be explained by the presence of the anodic phase $\beta\left(\mathrm{Al}_{3} \mathrm{Mg}_{2}\right)$ in the matrix of $\mathrm{Al}$.

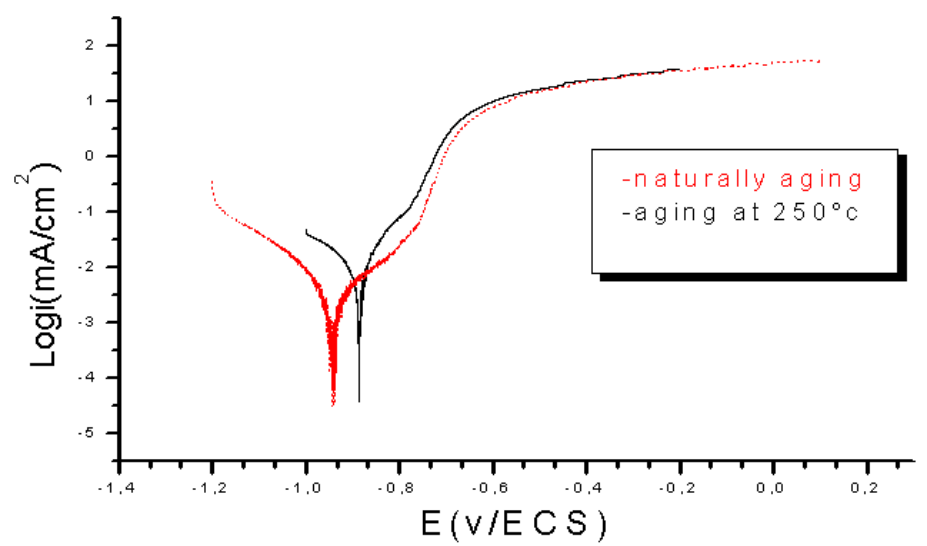

Fig. 3 Polarization curves of $\mathrm{Al}-10 \% \mathrm{Mg}$ in a $3.5 \% \mathrm{Nacl}$ solution

Table 5 The electrochemical parameters of the $\mathrm{Al}-10 \% \mathrm{Mg}$ samples in a $3.5 \% \mathrm{NaCl}$ solution

\begin{tabular}{|c|c|c|c|c|c|c|}
\hline & $\begin{array}{c}\mathrm{E}_{\text {corr }} \\
(\mathrm{mV})\end{array}$ & $\begin{array}{c}\mathrm{i}_{\text {corr }} \\
(\mu \mathrm{A} . \mathrm{cm} 2)\end{array}$ & $\begin{array}{c}\mathrm{R}_{\mathrm{p}} \\
\left(\mathrm{Kohm} . \mathrm{cm}^{2}\right)\end{array}$ & $\begin{array}{c}\mathrm{Ba} \\
(\mathrm{mV} / \mathrm{dec})\end{array}$ & $\begin{array}{c}\mathrm{Bc} \\
(\mathrm{mV} / \mathrm{dec})\end{array}$ & $\begin{array}{c}\mathrm{E}_{\mathrm{P}} \\
(\mathrm{mV})\end{array}$ \\
\hline $\mathrm{T}_{\text {room }}$ & -942.8 & 2.0409 & 4.41 & 121.7 & -93.2 & -757.6 \\
\hline $250^{\circ} \mathrm{c} / 24 \mathrm{~h}$ & -885.9 & 9.249 & 2.74 & 88.7 & -133.5 & -776.7 \\
\hline
\end{tabular}

\subsection{Electrochemical impedance spectroscopy (EIS) studies}

Fig. 4a presents a comparison of Nyquist responses obtained for the two treatments. The curve of the ageing at $250{ }^{\circ} \mathrm{C}$ for 24 hours has two loops; the first capacitive in the high frequency 
which was related to the electrochemical reactions corresponding to the degradation of the sample. And the second inductive to the low frequencies, this is due to the phenomenon of adsorption of the reaction products on the electrode. Thus the resistance of the polarisation $R_{p}$ of the system is the difference between the two diameters of two loops.

The curve EIS of ageing at room temperature exhibit one loop, a capacitive in the highfrequency region and Warburg impedance curve in the low frequency (see Fig. 4a). Warburg impedance is induced by the diffusion of corrosive reactants or species produced by corrosion [15]. Ageing at room temperature presents better protection. The response of the system to the frequency variations imposed may be represented by equivalent circuits. The equivalent circuit model of the corrosion system consists of the only two equivalent circuits which are shown in (Fig. 4b). The ageing at $250{ }^{\circ} \mathrm{C}$ during $24 \mathrm{~h}$ can be modelled by the equivalent circuit composed by elements: Re represents the electrolyte resistance. $\mathrm{R}_{\mathrm{ct}}$ and $\mathrm{CPE}_{2}$, are charge transfer resistance and pseudo double layer capacitance. $\mathrm{L}$ and $\mathrm{R}$ are respectively the inductance and resistance of the adsorbed species. And for ageing at room temperature, the equivalent circuit used includes; $\mathrm{R}_{\mathrm{e}}$ is the electrolyte
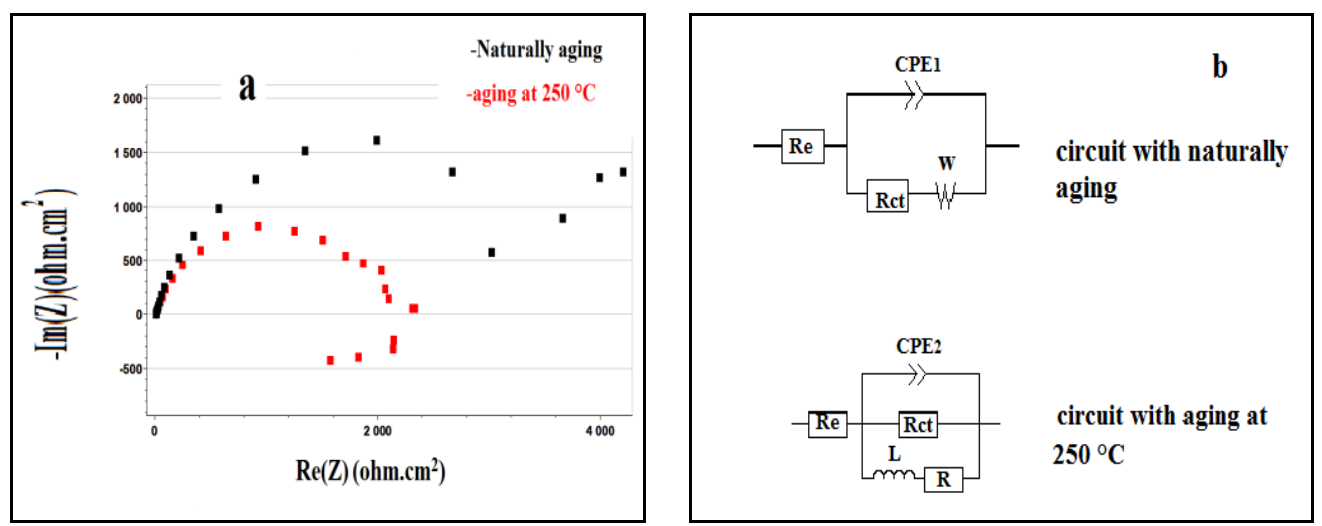

Fig. 4 (a) EIS diagram of $\mathrm{Al}-10 \%$ wt $\mathrm{Mg}$ alloy in $3.5 \% \mathrm{NaCl}$ solution, (b) Equivalent circuits which are used for modelling the EIS results

Resistance, $\mathrm{R}_{\mathrm{ct}}$ characterises the charge transfer process corresponding to the dissolution reaction. $\mathrm{CPE}_{1}$ is the pseudo double layer capacitance. The combination Rct and $\mathrm{CPE}_{1}$ is introduced to account for the presence of the surface film, and Warburg impedance (W) to account for the diffusion process. Resistance $R_{c t}$ is the same as of the polarisation. The CPE exponent is about 0.8452 (Tab. 6) and 0.8393 (Tab. 7) for both cases indicating a deviation from the ideal capacitive behaviour. This deviation is attributed to the heterogeneous nature of the surface due to the presence of precipitates in the alloy, pitting and local defects.

Table 6 Electrochemical impedance parameters for Al-10\% $\mathrm{Mg}$ alloy with ageing at $250{ }^{\circ} \mathrm{C}$.

\begin{tabular}{|c|c|c|c|c|c|}
\hline $\mathrm{R}_{\mathrm{s}}(\mathrm{ohm})$ & $\mathrm{R}_{\mathrm{ct}}(\mathrm{ohm})$ & $\mathrm{Q}\left(\mu \mathrm{F} \cdot \mathrm{cm}^{-2} \cdot \mathrm{s}^{\mathrm{a}-1}\right)$ & $\mathrm{a}$ & $\mathrm{R}(\mathrm{ohm})$ & $\mathrm{L}(\mathrm{H})$ \\
\hline 18.65 & 2224 & 40.18 & 0.8452 & 2872 & 66942 \\
\hline
\end{tabular}

Table 7 Electrochemical impedance parameters for Al-10\%wtMg alloy at naturally ageing.

\begin{tabular}{|c|c|c|c|c|}
\hline $\mathrm{R}_{\mathrm{e}}(\mathrm{ohm})$ & $\mathrm{R}_{\mathrm{ct}}(\mathrm{ohm})$ & $\mathrm{Q}\left(\mu \mathrm{F} \cdot \mathrm{cm}^{-2} \cdot \mathrm{s}^{\mathrm{a}-1}\right)$ & $\mathrm{a}$ & $\mathrm{W}\left(\mathrm{ohm} . \mathrm{s}^{1 / 2}\right)$ \\
\hline 12.88 & 3803 & 24.41 & 0.8398 & 481.7 \\
\hline
\end{tabular}




\section{Conclusion}

This work has studied the effect of heat treatment on the electrochemical behaviour of $\mathrm{Al}$ $10 \%$ wt $\mathrm{Mg}$ alloy; the results have been summarised as follows: electrochemical result shows a high activity of the alloy with the ageing at $250{ }^{\circ} \mathrm{C}$, it is due to the precipitates of the $\beta$ phase, which leads to the formation of pits. The inductive loop observed on the curve of impedance confirms the adsorption and penetration of chloride ions through the oxide film, and then we conclude that the ageing treatment did not improve the corrosion résistance. For the ageing at room temperature, the intermetallic particles and the porosity play a very important role in the electrochemical behaviour of the alloy. Good resistance to the corrosion, activity less important, high stability and protectiveness of the passive film are shown with the ageing at room temperature.

\section{References}

[1] E. Ghali: Corrosion Resistance of Aluminum and Magnesium Alloys, Understanding, Performance, and Testing, first ed., Wiley, New Jersey, 2010

[2] J.R. Davis: Corrosion of Aluminum and Aluminum Alloys, ASM International, 1999

[3] A. Alil, M. Popovic, T. Radetic, M. Zrilic, E. Romhanji: Journal of Alloys and Compounds, Vol. 625, 2015, p. 76-84, DOI:10.1016/j.jallcom.2014.11.063

[4] R. Goswami, G. Spanos, P.S. Pao, R.L. Holtz: Metall. Mater. Trans. Vol. 42, 2011, p. 34835, DOI: 10.1007/s11661-010-0262

[5] A. Zielinski. Materials Science, Vol. 34, 1998, No. 4, DOI: 10.1007/BF02360698

[6] F. Eckermann, T. Suter, P.J. Uggowitzer, A. Afseth, P. Schmutz: Electrochim. Acta, Vol. 54, 2008, p.844-855, DOI:10.1016/j.electacta.2008.05.078

[7] C. Vargel: Corrosion of Aluminium, eighth ed., Elsevier, Amsterdam, 2004

[8] K. Mizuno, A. Nylund, I. Olefjord,: Corros. Sci. Vol. 43, 2001, p. 381-396, DOI: 10.1016/S0010-938X(00)00069-X

[9] K.A. Yasakau, M.L. Zheludkevich, S.V. Lamaka, M.G.S. Ferreira: Electrochim. Acta, Vol. 52, 2007, p.7651-7659, DOI:10.1016/j.electacta.2006.12.072

[10]Y. Zhaoe et al.: Scripta Materialia, Vol. 89, 2014, p. 49-52, DOI: org/10.1016/scriptamat.2014.07.003

[11]T. Minoda, H. Yoshida: Metallurgical and materals transactions A. Vol. 33, 2002, p. 2891, DOI: $10.1007 / \mathrm{s} 11661-002-0274-3$

[12] S. Khireche, D. Boughrara, A. Kadri, L. Hamadou, N. Benbrahim: Corrosion Science, Vol. 87,2014, p.504-516, DOI :10.1016/j.corsci.2014.07.018

[13] V. Guillaumin, G. Mankowski: Corrosion Science. Vol. 41,1999, P. 421-438,

[14] W.J.Liang, P.A. Rometsch, L.F. Cao, N. Birbilis: Corrosion science,Vol.76,2013,p.119128, DOI:10.1016/j.corrsci.2013.06.035

[15]O. Belahssen, A. Chala, H. Ben Temam and S. Benramache: Royal Society of Chemistry RSC Advances, Vol. 4, 2014, No. 98, p. 52951-52958, DOI: 10.1039/C4RA08326A 